\title{
¿EXISTIÓ UN TRIBUNAL CONSTITUCIONAL EN MÉXICO?
}

\author{
RICARDO MARÍN MACÍAS ${ }^{1}$
}

Resumen: Este artículo explica si existió o no un Tribunal Constitucional en México a partir de los órganos y las funciones de control de la constitucionalidad que tuvieron vigencia en el país; la investigación abarca a las seis Constituciones históricas, incluyendo a la original de 1917 y sus principales reformas constitucionales de 1988,1995 y 2011.

Palabras clave: Tribunal Constitucional, Suprema Corte de Fusticia de la Nación, reformas judiciales, antecedentes, Supremo Poder Conservador.

Abstract: This article resolves if it existed or not a Constitutional Tribunal in Mexico according to the government body and functions related with constitutional review that had validity in the country; the reserch studies the six historical Constitutions, including the original one of 1917, and his principal constitutional reforms of 1988, 1995 and 2011.

Key words: Constitutional Tribunal, Supreme Court of Fustice of Mexico, judicial reforms, background, Supreme Custodian Power.

SumARIO: I. Introducción; II. Marco conceptual; III. Constitución Federal de los Estados Unidos Mexicanos de 1824; IV. Las Siete leyes constitucionales de 1835-1836; V. El Supremo Poder Conservador; VI. Bases Orgánicas de los Estados Unidos Mexicanos de 1843; VII. Acta constitutiva y de reformas de 1847; VIII. Constitución Federal de los Estados Unidos Mexicanos de 1857; IX. Constitución Política de los Estados Unidos Mexicanos de 1917; X. Reforma constitucional del Poder Judicial de la Federación de 1988; XI. Reforma constitucional del Poder Judicial de la Federación de 1995; XII. La Décima Época; XIII. Conclusiones; XIV. Fuentes.

1 Estudiante de la maestría en Derecho en el Programa de Posgrado en Derecho de la UNAM. Agradezco al Consejo Nacional de Ciencia y Tecnología (CONACYT) por el apoyo como becario del Programa de Maestría en Derecho de la UNAM. 
Las instituciones jurídicas tienden a adecuarse a las exigencias mutables de la vida práctica, tal vez con un cierto desfase temporal, de excesivo anticipo o de excesivo retraso respecto al desenvolvimiento de las circunstancias.

Mauro Cappelletti

\section{INTRODUCCIÓN}

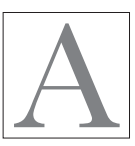

partir de 1988 se instaló un debate en México sobre la naturaleza jurídica de la Suprema Corte de Justicia de la Nación, debate que a pesar del transcurso de los años y las reformas judiciales sigue vigente.

Este debate de actualidad se ha extendido hacia uno de carácter histórico para dilucidar si alguna vez se registró en la vida institucional de México un tribunal constitucional.

El objetivo de este trabajo es conocer si existen o no antecedentes en México de un tribunal constitucional, se señalarán los puntos de inflexión que hubo en el diseño del poder judicial federal, y en específico de sus tribunales terminales, desde un enfoque históricoconstitucional; a fin de entender la relación entre la Suprema Corte de Justicia de la Nación y los tribunales constitucionales.

El tribunal constitucional es el último eslabón de una cadena histórica sobre el control del poder que se construyó a base de prueba y error. Por tanto, para su estudio histórico se debe hacer una separación entre el órgano y la función de control de la constitucionalidad.

De ahí que, al investigar los antecedentes históricos del tribunal constitucional se debe aludir a los conceptos, teorías, principios e instituciones que fungen como sus presupuestos básicos, ya sean orgánicos o funcionales, por ejemplo: el control de regularidad, anulación e inaplicación de la ley, independencia judicial, supremacía constitucional y las cortes superiores.

Los antecedentes del tribunal constitucional en México se exponen a través de las diversas Constituciones Generales que tuvieron vigencia. Hay que hacer notar que de todas las Constituciones de 
los Estados Unidos Mexicanos, sólo una se gestó en el siglo pasado, mientras que el resto de las Constituciones fueron del siglo XIX. ${ }^{2}$

\section{il. Marco conceptual}

El tribunal constitucional es la instancia jurisdiccional de un Estado que, de modo excluyente, determina la constitucionalidad de normas, actos y omisiones de las autoridades. Sus características son las siguientes:

1) Colegiado: debe estar conformado por un grupo de personas, pero el número preciso de juristas que lo integran se adecua a las circunstancias de cada Estado. ${ }^{3}$

2) Unicidad: es un órgano excluyente o concentrado porque descarta a los demás tribunales de conocer el control de la constitucionalidad.

3) Especializado: es exclusivo, porque sus atribuciones están plenamente delimitadas al control de la constitucionalidad, aunque como excepción puede abarcar la determinación de la responsabilidad de altos funcionarios del Estado. ${ }^{4}$

4) Jurisdiccional: única instancia que está facultada para resolver a través de un proceso el fondo y la forma de los litigios. $^{5}$

2 Cfr. Secretaría de Gobernación, Antecedentes Históricos y Constituciones Políticas de los Estados Unidos Mexicanos, México, Dirección General de Compilación y Consulta del Orden Jurídico Nacional de la Secretaría de Gobernación, 2006, p. 15.

${ }^{3}$ Cfr. Hans Kelsen, La garantía jurisdiccional de la Constitución, Biblioteca Jurídica Virtual del Instituto de Investigaciones Jurídicas de la UNAM, disponible en: <http://www.bibliojuridica.org/libros/libro.htm?l=31>, [Fecha de consulta: 21 de diciembre de 2015], p. 57.

4 Cfr. Miguel Covián Andrade, La Suprema Corte y el control de la constitucionalidad (diez años de fallas e imprecisiones), México, CEDIP, 2005, pp. 79 y ss.

5 Idem. 
5) Está integrado por especialistas en el control de la constitucionalidad debido a que su tarea es eminentemente técnico-constitucional. Cabe mencionar que existe una polémica sobre la elección de jueces de carrera, académicos o una combinación de ambos para su integración. ${ }^{6}$

6) Autónomo e independiente a cualquier otro poder, incluyendo al judicial, por lo que cuenta con atribuciones para dictar y ejecutar sus fallos.

7) Es un poder constituido, de tal suerte que reúne las características de ser permanente, limitado, derivado y constitucional (en contraposición a los órganos secundarios que son legales).

8) Sus procedimientos se guían por el principio de publicidad.

9) La designación democrática de sus integrantes: no se atribuye a un solo cuerpo político, sino que deriva de un poder real de nombramiento por parte de los órganos estatales, a fin de asegurar un equilibrio constitucional y el control efectivo. $^{7}$

Hay que destacar que ningún órgano o persona física que ejerce el control de la constitucionalidad está exento de crítica: ya sea el poder legislativo, ejecutivo o judicial. Por lo que se refiere al tribunal constitucional, Carl Schmitt formuló las críticas más recalcitrantes contra esta institución en el debate que sostuvo con Hans Kelsen a través de sus respectivas publicaciones. ${ }^{8}$ A continuación se exponen las principales críticas de Schmitt, con la respectiva réplica de Kelsen.

6 Idem.

7 Ibidem, p. 21.

8 Schmitt, Carl, La defensa de la Constitución. Estudio acerca de las diversas especies y posibilidades de salvaguardia de la Constitución, España, Tecnos, 1983; y Hans Kelsen, op. cit. 
En primer lugar, se sostiene que el tribunal constitucional es incompatible con la soberanía del Parlamento. Sobre este argumento, H. Kelsen aclara: la soberanía reside en el Estado, en todos sus órganos. El único que concentra la soberanía, y de forma temporal, es el Poder Constituyente. El parlamento, al ser un poder constituido (al igual que el tribunal constitucional), es tan soberano como el resto de los órganos estatales. ${ }^{9}$

En segundo lugar, según la crítica en contra del tribunal constitucional, éste transgrede el principio de división de poderes. Se argumenta una supuesta tensión teórica entre la división de poderes y el control de la constitucionalidad dado que éste permite la intromisión en las competencias de otros poderes del Estado; por lo que atenta contra de la división de poderes.

Sin embargo, esta premisa parte de una incorrecta comprensión de dicho principio, pues no debe entenderse como una separación tajante de poderes si se atiende al hecho de que todos los órganos (legislativo, ejecutivo y judicial) realizan todas las funciones; "plantear la idea de la división de poderes separando los órganos del Estado de un modo definitivo e irreconciliable, es algo completamente alejado de la realidad histórica y de la misma doctrina política."10

De hecho, la división de poderes, junto con la supremacía y rigidez constitucional, es presupuesto del control de la constitucionalidad, cuyo propósito es garantizarlo, no contradecirlo.

El límite de todos los poderes, sin excepción, es la Constitución. En este contexto, el tribunal constitucional no invade las funciones del poder legislativo, más bien las limita. Huelga decir que un órgano legítimo de control de la constitucionalidad divide aún más el poder, no lo centraliza.

9 Cfr. Hans Kelsen, op. cit., p. 52.

10 Lorenzo Córdova Vianello, "El sistema presidencial en México. Orígenes y Razones" en Miguel Carbonell (dir.), Ensayos sobre Presidencialismo Mexicano, México, Aldus, 1994, p. 10. 
En tercer lugar, Schmitt afirma que el tribunal constitucional sólo propicia la politización de la jurisdicción, por lo que las consideraciones políticas dominan todas las decisiones de anulación de las leyes. Por el contrario, la actuación del tribunal constitucional está determinada por la propia Constitución, su naturaleza jurídica no la convierte en un objeto apolítico, pero sí apartidista.

También sería iluso pensar que se pueden resolver todos los conflictos políticos en los tribunales; sin embargo, sí se pueden resolver los de mayor incidencia para la sociedad. Lo más importante es que el tribunal constitucional ofrece un proceso racional ${ }^{11}$ de toma de decisiones, la deliberación y confrontación de ideas de forma pública a través de la lógica y de la argumentación jurídicas, lo que redunda en la legitimidad de la decisión.

En cuarto lugar, se critica que las decisiones del tribunal constitucional son irrecurribles por lo que se convierten en "dogmas". La réplica es: si bien la resolución de una cuestión de constitucionalidad por parte del tribunal es cosa juzgada, atiende a una cuestión lógica que es evitar el "espiral infinito" de impugnaciones.

En este sentido, las decisiones de la única instancia no pueden ser atacadas por una razón de Estado, pero la diferencia es el camino para llegar a dicha decisión, el cual debe ser fundado y motivado. Esto no implica que esa decisión quede estática, sino que puede cambiar a raíz de un nuevo planteamiento (que puede ser abstracto), con la debida motivación.

En quinto lugar, se argumenta que la instauración de un tribunal constitucional favorece un órgano libre de todo control de la constitucionalidad. Es decir, el órgano de control carece de control alguno y esto rompe el equilibro del Estado constitucional. Según

11 Lo irracional significa "quedarse en el mundo particular", mientras que lo racional se refiere a estar "dentro de la unidad y comunidad de la razón". Véase Rolando Tamayo y Salmorán, Razonamiento y Argumentación furídica. El paradigma de la racionalidad y la ciencia del derecho, México, UNAM, 2007, p. 36. 
Schmitt, se abandona el "despotismo del legislador" para entrar a la era de la "arbitrariedad de los jueces" o "aristocracia de la toga".

Ante esta presunta aporía, Kelsen atina a responder que, en principio, el tribunal constitucional no puede invadir competencias de otros poderes sencillamente porque no se le encomiendan tareas de gobierno o de legislación. Esto es cierto, siempre y cuando se trate de un órgano exclusivo y excluyente.

Si se acotan las competencias del tribunal constitucional, se evita crear otro órgano que revise al de control; claro está que eso requiere de una depurada técnica constitucional. Así, las funciones de un tribunal constitucional deben limitarse a:

- Revisar las normas, declararlas inconstitucionales en su caso, eliminarlas del ordenamiento jurídico y señalar qué se va a aplicar, en cualquier área del Estado.

- Verificar el procedimiento legislativo y las reformas a la Constitución.

- Fijar el sentido y alcance del contenido de las normas constitucionales.

- La composición de conflictos entre órganos del Estado y órdenes de gobierno.

- Atender las acusaciones contra altos servidores públicos.

- Examinar la constitucionalidad de los partidos políticos.

En definitiva, la tarea de un tribunal constitucional es, precisamente, construir los límites, sentido y alcances de los principios constitucionales. No puede suprimirlos, pero debe y puede explicarlos.

\section{ili. Constitución Federal de los Estados Unidos MeXicanos de 1824}

Después de que México obtuvo su independencia en 1821, se instauró el primer imperio mexicano, y se elaboró el Reglamento Provi- 
sional Político del Imperio Mexicano. Sin embargo, éste nunca entró en vigor puesto que dicho documento se publicó el mismo mes en el que Agustín de Iturbide abdicó (marzo de 1823). ${ }^{12}$

Por tanto, la Constitución Federal de los Estados Unidos Mexicanos fue la primera de México como país independiente. Funcionó del 4 de octubre de 1824 hasta el 15 de diciembre de 1835 .

En ella se establecieron varios mecanismos de defensa de la Constitución, por ejemplo, la división de poderes en el artículo $6^{\circ} \mathrm{y}$ la tutela del cumplimiento de la Constitución, a cargo del Consejo de Gobierno en el artículo 116, aunque no estableció procedimientos para el caso de incumplimiento.

El máximo órgano jurisdiccional se denominó Corte Suprema de Justicia. Ésta se compuso por once Ministros y un fiscal (artículo 124 constitucional) y, de acuerdo con la lógica federalista, la integración de este órgano se descentralizó, puesto que los Ministros eran elegidos por las legislaturas de los Estados por mayoría absoluta de votos (26 entidades territoriales en aquel entonces), conforme al artículo $127 .{ }^{13}$

Cabe destacar la configuración singular de un tribunal para juzgar a los Ministros de la Corte Suprema de Justicia, dispuesto en el artículo 139.

Art. 139. Para juzgar á los individuos de la corte suprema de justicia, elegirá la cámara de diputados, votando por estados en el primer mes de las sesiones ordinarias de cada bienio, veinte y cuatro individuos, que no sean del Congreso general y que tengan las cualidades que los Ministros de dicha corte suprema: de estos se sacarán por suerte un fiscal y un número de jueces igual á aquel de que conste

12 Antecedentes Históricos y Constituciones Políticas de los Estados Unidos Mexicanos, op. cit., p. 57.

13 "Art. 127. La elección de los individuos de la corte suprema de justicia será en un mismo dia por las legislaturas de los estados á mayoria absoluta de votos." Ibidem, p. 120. Las citas de los artículos aparecen conforme al texto original del siglo XIX. 
la primera sala de la corte; y cuando fuere necesario, procederá la misma cámara, y en sus recesos el consejo de gobierno, á sacar del mismo modo los jueces de las otras salas. ${ }^{14}$

Mientras que en el artículo 137, fracción I constitucional se instituyó un antecedente discreto de la controversia constitucional entre las atribuciones de la Corte Suprema, como una forma de control de federalidad. Además,

dicha carta federal confirió a la Suprema Corte (de acuerdo con el artículo 137, fracción V, inciso sexto) la facultad de conocer de las violaciones a la Constitución y las leyes federales [...] pero dicho precepto no llegó a reglamentarse y por lo mismo careció de aplicación. ${ }^{15}$

La Constitución de 1824 no instituyó un tribunal constitucional. La ausencia es entendible dado que la propia doctrina sobre el control de la constitucionalidad aún se estaba forjando (hasta la segunda mitad del siglo XIX se introdujeron en Europa órganos concentrados con carácter judicial). Por otra parte, la prioridad de los constituyentes de 1824 fue asegurar la independencia de México, así como la forma de Estado y de Gobierno; es decir, primero se debía alcanzar un acuerdo sobre los temas básicos para un país naciente.

IV. LAs Siete Leyes constitucionales de 1835-1836

La segunda Constitución del Estado Mexicano fueron las Leyes constitucionales. Se les llama así porque "en lugar de confeccionar una nueva ley fundamental, se prefirió expedir leyes constitucionales. La

\footnotetext{
14 Ibidem, p. 122.

15 Héctor Fix Zamudio y Salvador Valencia Carmona, Derecho Constitucional Mexicano y Comparado, $4^{\mathrm{a}}$ ed., México, Porrúa-UNAM, 2005, pp. 820-821.
} 
primera ley fue promulgada el 15 de diciembre de 1835 y [...] las seis leyes restantes fueron aprobadas el 9 de diciembre de 1836". ${ }^{16}$

Esto se debió a las circunstancias políticas, puesto que los conservadores reunieron la suficiente fuerza política en el año de 1835 para "autoproclamarse" como Congreso Constituyente.

$[\mathrm{U}]$ no de los principales propósitos del Congreso sería dar un giro a la forma de Estado de nuestra nación [...] se señaló en el decreto del 2 de mayo de 1835, que en el Congreso residían, por voluntad de la nación, todas las facultades extraconstitucionales necesarias para hacer, a la Constitución de 1824, alteraciones que creyeran conveniente; o sea, se estaba proclamando un Congreso Constituyente. ${ }^{17}$

\section{v. El Supremo Poder Conservador}

La segunda ley constitucional de 1836 instituyó al Supremo Poder Conservador. Su nombre derivó de su función, que era conservar las Siete leyes constitucionales. Era el cuarto poder encargado de vigilar la actuación del legislativo, ejecutivo y judicial. Se constituyó en mayo de 1837, y se suprimió en septiembre de 1841 por el Plan de Tacubaya. ${ }^{18}$

El Supremo Poder Conservador es el primer antecedente en México de un órgano de control de la constitucionalidad. Pero no fue un órgano exclusivo porque tenía otras atribuciones aparte del control de la constitucionalidad (artículo 12 de la segunda ley constitucional).

Tampoco fue un poder excluyente. El artículo $5^{\circ}$ de la séptima ley constitucional atribuyó de forma simultánea al Congreso Gene-

16 Enrique Quiroz Acosta, Teoría de la Constitución, $3^{\mathrm{a}}$ ed., México, Porrúa, 2005, p. 300 .

17 Ibidem, p. 299.

18 Cfr. Raúl Pérez Johnston, El Supremo poder conservador y su sentencia de muerte: la ley sobre ladrones del 13 de marzo de 1840, Biblioteca Jurídica Virtual del Instituto de Investigaciones Jurídicas de la UNAM, disponible en: <http://biblio.juridicas.unam. $\mathrm{mx} /$ libros/6/2556/22.pdf>, [Fecha de consulta: 21 de diciembre de 2015], p. 438. 
ral la resolución de las dudas sobre artículos constitucionales, ${ }^{19}$ por lo que también tenía atribuciones de control de la constitucionalidad. Esto tuvo varias repercusiones, puesto que con esta disposición constitucional el Supremo Poder Conservador perdió la calidad de órgano concentrado, y por ende excluyente; de hecho, generó una duplicidad de funciones que terminó en un conflicto entre los poderes.

Actuó por vía directa a petición de parte - reservado a órganos originarios del Estado en el artículo 12, fracciones I, II y III de la segunda ley constitucional-, su objeto de control eran las leyes $\mathrm{y}$ actos inconstitucionales del legislativo, ejecutivo y judicial, pero no contempló el control de las omisiones legislativas (artículo 12, fracciones I y II de la ley constitucional citada).

Sus sentencias tuvieron efectos declarativos de nulidad absoluta, según las fracciones I, II, y III del mismo artículo y ley constitucional citados. Además, tuvo la atribución político-electoral de calificar los comicios de los senadores.

Se conformó por cinco personas y era renovado cada dos años de manera escalonada. Cabe mencionar que el procedimiento de integración daba cabida a las legislaturas para postular candidatos; sin embargo, de acuerdo con la forma de Estado en esa época, la decisión final se centralizó en la Cámara de Diputados (artículo $3^{\circ}$ de la segunda ley constitucional).

El Supremo Poder Conservador no fue un tribunal constitucional, porque la naturaleza de este órgano era política. Primero, porque sus integrantes debían haber desempeñado el cargo de presidente de la República, vicepresidente de la República, senador, diputado, secretario de despacho o magistrado de la Suprema Corte, según el artículo 10, fracción III, de la segunda ley constitucional. Segundo, porque existió un desequilibrio constitucional en su procedimien-

19 "Art. 5. Sólo al Congreso general toca resolver las dudas de artículos constitucionales." Antecedentes Históricos y Constituciones Politicas de los Estados Unidos Mexicanos, op. cit., p. 179. 
to de integración; y, tercero, porque sus resoluciones sólo tenían efectos declarativos, según el artículo 12, fracciones I, II y III de la citada ley.

Los términos en los que ocurrió su crisis institucional son los siguientes: ${ }^{20}$ Anastasio Bustamante, en su último ciclo como presidente de México, emitió el decreto del 5 de octubre de 1839 dirigido a la comandancia militar de Puebla, para extender la jurisdicción militar a los delitos de robo cometidos por civiles, como una medida para contrarrestar la delincuencia y la violencia exacerbadas.

La Alta Corte (el máximo tribunal dentro de la esfera judicial) excitó al Supremo Poder Conservador para que se manifestara al respecto, por lo que éste declaró la inconstitucionalidad del decreto. Ante esto, el Presidente anuló motu propio su decreto, desatendiendo el orden constitucional y, por si fuera poco, presentó el contenido de ese decreto ante el Congreso General como la iniciativa de ley sobre ladrones el 13 de marzo de 1840, en un intento burdo del Ejecutivo para ejercer poderes de excepción a través de una ley marcial.

La ley se aprobó en marzo de 1840. El ámbito material de aplicación era penal, el ámbito espacial se extendió a toda la República mexicana y el ámbito personal se circunscribió a los ladrones, excepto a los carteristas y a los que cometieran robos de cuantía menor sin violencia. El Supremo Poder Conservador anuló los artículos $1^{\circ}, 5^{\circ}$ y $7^{\circ}$ de dicha ley, por ser contrarios a las normas constitucionales al regular tribunales especiales, no cumplir con el proceso legislativo y ordenar a los jueces a desempeñarse como asesores del tribunal militar. Transcurrieron dos meses entre la publicación de la ley de ladrones y su declaración de inconstitucionalidad por parte del Conservador.

Sin embargo, Anastasio Bustamante no sólo se negó a acatar el fallo del Supremo Poder Conservador, sino que emitió una circular para ordenar la aplicación de la ley de ladrones -lo cual implicaba

20 Véase Raúl Pérez Johnston, op. cit., pp. 443 y ss. 
alta traición conforme al artículo 15 de la segunda ley constitucional- ${ }^{21}$ incluso rebatió el dictamen; aunque esta atribución sólo la concedía el artículo citado cuando dicha resolución fuera sin arreglo a las disposiciones constitucionales. Así las cosas, el presidente reviró dos falacias: que la resolución del Supremo Poder Conservador fue extemporánea, y que no manifestaba la voluntad del órgano colegiado.

Ante esta situación de crisis constitucional, desafortunadamente el Supremo Poder Conservador cayó en la mecánica del Ejecutivo y sin ningún fundamento constitucional le rebatió al presidente, en lugar de ordenar el cumplimiento del fallo.

Así las cosas, el Supremo Poder Conservador contraargumentó que la resolución se formuló en tiempo y forma puesto que el término se contó por meses completos y éste empezó a correr al día siguiente de la sanción de la ley inconstitucional y, además, la Segunda Ley Constitucional sólo exigía tres votos de sus integrantes para que tuviera efectos el dictamen (la resolución del Conservador se decidió por cuatro votos en favor de la inconstitucionalidad de la referida ley). ${ }^{22}$

Todas las actuaciones del Supremo Poder Conservador que fueron posteriores al incumplimiento de la sentencia por parte del Ejecutivo fueron lógicamente inconstitucionales, lo que reflejó una grave contradicción con la finalidad de esa institución.

El Supremo Poder Conservador no ordenó el incumplimiento porque estaba ante una aporía: no tenía medios para obligar a Anastasio Bustamante a acatar la resolución de la discordia y, de afirmar

21 "Art. 15. Toda declaracion y disposición de dicho Supremo Poder Conservador dada con arreglo á las disposiciones precedentes, y citando la respectiva, debe ser obedecida al momento y sin réplica por todas las personas á quien se dirija y corresponda la ejecución.

La formal desobediencia se tendrá por crimen de alta traición." Antecedentes Históricos y Constituciones Políticas de los Estados Unidos Mexicanos, op. cit., p. 143.

22 Raúl Pérez Johnston, op. cit., p. 453. 
el incumplimiento del ejecutivo, automáticamente lo acusaba de traición a la patria y arrastraba al país a otro levantamiento armado.

La Alta Corte de Justicia apoyó al Conservador puesto que se rehusó a aplicar la ley de ladrones, pero el Congreso apoyó incondicionalmente al ejecutivo en un acto de subordinación rapaz. En estas circunstancias, Anastasio Bustamante envió el 5 de junio de 1840 la iniciativa de la Ley Orgánica del Supremo Poder Conservador al Congreso General, para delimitar las atribuciones del cuarto poder. De esta forma, "el Legislativo se habría convertido en una segunda instancia no autorizada constitucionalmente de las sentencias del Conservador". ${ }^{23}$

[E]l Conservador no pudo ejercer su alta misión constitucional, entre otras causas, porque las autoridades del momento no estaban conscientes del valor de un defensor de la Constitución y nada querían saber de controles al ejercicio de sus esferas de poder; situación en la que el Conservador estaba llamado a fracasar, indefenso ante la fuerza fáctica de la milicia en el poder [...] ante un Poder Ejecutivo que tuvo la fuerza institucional de las armas para sobreponerse a la contienda, y así, destruidos los medios de control, el poder absoluto afloró e hizo evidente el fracaso del sistema constitucional de las Siete Leyes. ${ }^{24}$

Las causas de su fracaso institucional fueron "la falta de atribuciones para poder hacer cumplir sus resoluciones, así como el que todavía quedara el Congreso facultado para dirimir dudas sobre interpretación de la Constitución". ${ }^{25}$ En pocas palabras, un poder del Estado que no tiene atribuciones para hacer cumplir sus resoluciones es inexistente puesto que el cumplimiento de sus decisiones depende de la buena voluntad de los afectados.

\footnotetext{
23 Ibidem, p. 466.

24 Ibidem, p. 474.

25 Ibidem, p. 467.
} 


\section{vi. Bases Orgánicas de los Estados Unidos Mexicanos DE 1843}

El hundimiento del sistema constitucional de 1836, que derivó del conflicto entre los cuatro poderes, inició una etapa de desorden constitucional que coincidió con el movimiento separatista en Yucatán. Esta entidad territorial promulgó la Carta del Estado mexicano de Tucatán el 16 de mayo de 1841, que estuvo en vigor durante nueve años y cuyo autor intelectual fue Manuel Crescencio Rejón.

Este documento fue el primero, no sólo en México, sino en América Latina, en incorporar al sistema jurídico un control de la constitucionalidad de carácter judicial y difuso; a través de un proceso denominado amparo, singular síntesis del control de la constitucionalidad y legalidad y, a la vez, instrumento para tutelar los derechos fundamentales. Se estableció en los artículos 8, 9 y 62 de la Constitución yucateca. ${ }^{26}$

26 Constitución Política del Estado de Fucatán de 1841, disponible en:<http://www. pdi.uady. mx/docs/evid02/6.\%20Accin/COMPILACIONES/COMPILA\%20 AMPARO $\% 20 I I \% 20 P D F /$ constitucoin $\% 201841 . p d f>$. [Fecha de consulta: 21 de diciembre de 2015], pp. 4, 5 y 13:

Artículo 8.-Los jueces de primera instancia ampararán en el goce de los derechos garantidos por el artículo anterior, a los que les pidan su protección contra cualesquier funcionarios que no correspondan al orden judicial, decidiendo brevemente y sumariamente las cuestiones que se susciten sobre los asuntos indicados.

Artículo 9.-De los atentados cometidos por los jueces contra los citados derechos, conocerán sus respectivos superiores con la misma preferencia de que se ha hablado en el artículo precedente; remediando desde luego el mal que les reclame, y enjuiciando inmediatamente al conciliador de las mencionadas garantías.

Artículo 62.-Corresponde a este tribunal reunido: [Corte Suprema de Justicia del Estado de Yucatán]

1. Amparar en el goce de sus derechos a los que le pidan su protección contra las leyes y decretos de la legislatura que sean contrarias al texto literal de la Constitución, o contra las providencias del gobernador, cuando en ellas se hubiesen infringido el código fundamental en los términos expresados, limitán- 
Cabe agregar que, en este Ordenamiento Fundamental yucateco no es posible vislumbrar algún antecedente orgánico del tribunal constitucional, por el contrario, la inclusión del amparo excluía la posibilidad de un órgano concentrado de control de la constitucionalidad.

En 1842, los liberales intentaron restaurar el proyecto federal de la Constitución de 1824 y convocaron a un Congreso Constituyente. Sin embargo, la reacción de los conservadores fue disolver dicho Congreso en el momento en el que observaron que el proyecto no respondía a la forma de Estado unitario, y en contraposición promulgaron las Bases Orgánicas de los Estados Unidos Mexicanos el 14 de junio de 1843, la cual tuvo una vigencia efímera de tres años en medio de levantamientos militares y conatos de intervención extranjera. Se eliminó el Supremo Poder Conservador, así como cualquier atisbo de un tribunal constitucional autónomo a los tres poderes tradicionales.

En esta Constitución, la Suprema Corte de Justicia nuevamente se conformó por once ministros y un fiscal, según el artículo 116. En materia de control jurisdiccional de la constitucionalidad, el artículo 118, fracción XII, de las Bases Orgánicas, facultó a la Suprema Corte para resolver los recursos de nulidad interpuestos contra las sentencias de los tribunales locales, aunque no aclara el parámetro de confrontación de dicho recurso. ${ }^{27}$

dose en ambos casos, a reparar el agravio en la parte en que la Constitución hubiese sido violada.

27 "118. Son facultades de la Corte Suprema de Justicia: [...] XII. Conocer de los recursos de nulidad que se interpongan contras las sentencias dadas en última instancia por los tribunales superiores de los departamentos. Mas si conviniere á la parte, podrá interponer el recurso ante el tribunal del departamento mas inmediato, siendo colegiado." Antecedentes Históricos y Constituciones Políticas de los Estados Unidos Mexicanos, op. cit., p. 206. 


\section{Vil. Acta constitutiva y de Reformas de 1847}

En 1847, durante la guerra de intervención estadounidense y con la mitad del territorio nacional ocupado, los liberales convocaron a un congreso extraordinario constituyente, nuevamente con la finalidad de reinstaurar la Constitución de 1824. En este contexto, el constituyente Mariano Otero formuló un voto particular respecto del dictamen de la mayoría del Congreso extraordinario de $1847 .{ }^{28}$

Otero estaba en favor de la reinstauración de la Constitución de 1824, pero con las modificaciones pertinentes para su cabal cumplimiento. Con base en La democracia en América, de Alexis de Tocqueville y las ideas de Manuel Crescencio Rejón instituidas en la Constitución yucateca de 1841, el jurista jalisciense propuso en el artículo 19 de su proyecto de Acta de reformas la incorporación del amparo en la Constitución Federal.

Además, en el artículo 16 de su proyecto de acta de reformas planteó que la mayoría de las Legislaturas de los estados tuvieran la facultad de decidir la constitucionalidad de las normas expedidas por el Congreso General, es decir, propuso la acción de inconstitucionalidad; ${ }^{29}$ esta iniciativa estaba en completa concordancia con la

28 Cfr. Mariano Otero, "Voto particular de Mariano Otero (5 de abril de 1847)", en La Suprema Corte de Justicia sus leyes y sus hombres, México, Suprema Corte de Justicia de la Nación, 1985, pp. 127-141.

29 Antecedentes Históricos y Constituciones Políticas de los Estados Unidos Mexicanos, op. cit., p. 229:

La propuesta de acción de inconstitucionalidad se aprobó con cambios específicos, y se estableció en el artículo 23 del Acta constitutiva y de reformas con la siguiente redacción: "Si dentro de un mes de publicada una ley del Congreso general, fuere reclamada como anti-constitucional, ó por el Presidente, de acuerdo a su ministerio, ó por diez diputados, ó seis Senadores, ó tres Legislaturas, la suprema corte, ante la que se hará el reclamo, someterá la ley al ecsámen de las Legislaturas, las que dentro de tres meses, y precisamente en un mismo dia, darán su voto.

Las declaraciones se remitirán á la suprema corte, y ésta publicará el resultado, quedando anulada la ley, si así lo resolviere la mayoría de las Legislaturas. [sic] 
teoría del federalismo, en virtud de que son las entidades federativas las que crean a la Federación.

El 18 de mayo de 1847 se expidió el Acta constitutiva y de reformas. Las principales modificaciones a la Constitución de 1824 fueron la incorporación de un capítulo de derechos fundamentales, la eliminación de la vicepresidencia de la República y la integración de la Suprema Corte de Justicia por elección popular.

Al final, se aprobó la constitucionalización del proceso de amparo con la cláusula de relatividad de las sentencias y se cristalizó en el artículo 25 del Acta de reformas. ${ }^{30}$ Aunque el amparo fue una contribución de la periferia hacia el centro, este medio de control de la constitucionalidad enfrentó muchas críticas y obstáculos durante el siglo XIX, puesto que su federalización implicó que el Poder Judicial de la Federación podía contrarrestar las decisiones de las autoridades federales y locales. ${ }^{31}$ Si bien careció de reglamentación hasta 1861, esto no impidió su aplicación intermitente, como lo demuestra la primera emisión de una sentencia de amparo en el año de $1849 .{ }^{32}$

El Acta constitutiva y de reformas no instituyó ningún órgano homólogo a un tribunal constitucional, por el contrario, se decantó por un sistema de control con órganos difusos, entre otros motivos,

зо "Art. 25. Los tribunales de la Federación ampararán á cualquiera habitante de la república en el ejercicio y conservación de los derechos que le concedan esta Constitucion y las leyes constitucionales, contra todo ataque de los poderes legislativo y ejecutivo, ya de la Federación, ya de los Estados; limitándose dichos tribunales á impartir su protección en el caso particular sobre que verse el proceso, sin hacer ninguna declaración general respecto de la ley ó del acto que lo motivare." Idem.

31 Cfr. José Antonio Caballero, "De la marginalidad a los reflectores. El renacimiento de la administración de justicia en México" en Ilán Bizberg y Lorenzo Meyer (coords.), Una historia Contemporánea de México: Las instituciones, México, Océano/ El Colegio de México, 2008, t. 3, p. 164.

32 Cfr. Enrique Arizpe Narro, La primera sentencia de amparo, México, Coordinación de Compilación y Sistematización de la Suprema Corte de Justicia de la Nación, 2006, p. 50. 
porque en ese entonces aún era reciente el recuerdo del Supremo Poder Conservador, que representó el fracaso de un cuarto poder en México.

Así las cosas, mientras los políticos mexicanos hicieron política, los políticos estadounidenses hicieron la guerra y "el 14 de septiembre de 1847 fue izada la bandera de los Estados Unidos en el Palacio Nacional de México, mientras el gobierno derrotado se instala en Querétaro". ${ }^{33}$

La Constitución de 1847 continuó en vigor al finalizar la guerra y aun después de la firma de los Tratados de Guadalupe Hidalgo, pero tuvo que lidiar con el regreso de Antonio López de Santa Anna quien en 1853 expidió las Bases para la administración de la República, hasta la promulgación de la Constitución, de carácter transitorias porque la revolución de Ayutla terminó con la dictadura de Santa Anna en 1855. ${ }^{34}$ "Entre 1821 y 1850 reinó la inquietud en todos los órdenes. En treinta años hubo cincuenta gobiernos, casi todos producto del cuartelazo; once de ellos presididos por el general Santa Anna." 35

\section{vili. Constitución Federal de los Estados Unidos MeXICANOS DE 1857}

La Constitución Federal de los Estados Unidos Mexicanos del 12 de febrero de 1857 fue la quinta Constitución del México independiente. En este sistema constitucional, la Suprema Corte de Justicia se integró por once Ministros propietarios, cuatro supernumerarios, un fiscal y un procurador general.

De esta forma, el procurador general salió de la esfera del ejecutivo y se adjuntó a la rama del poder judicial. El procedimiento de

33 Daniel Cosío Villegas et al., Historia Mínima de México, México, El Colegio de México, 1983, p. 101.

34 Cfr. Antecedentes Históricos y Constituciones Políticas de los Estados Unidos Mexicanos, op. cit., p. 235.

35 Cosío Villegas, Daniel, et al., op. cit., p. 102. 
integración de la Suprema Corte se estableció por elección indirecta, según el artículo 92 constitucional. ${ }^{36}$ La elección indirecta en el siglo XIX

consistía en un conjunto sucesivo de elecciones en las cuales un grupo de "ciudadanos" eligen a otros de mayor ilustración llamados "compromisarios". Éstos a su vez eligen a otros ciudadanos de mayores luces llamados electores secundarios quienes finalmente eligen a las personas que ocuparán los puestos. ${ }^{37}$

En relación con la defensa de la Constitución, la de 1857 mostró avances conforme al título IV que reguló la responsabilidad de los servidores públicos. Por otra parte, la subsistencia del amparo en la Constitución se estableció en el artículo 101.

No obstante lo anterior, en esta Constitución no se encuentra alguna institución homóloga a un tribunal constitucional, ya que la Suprema Corte funcionó más bien como un tribunal de agravios. ${ }^{38}$

\section{ix. Constitución Política de los Estados Unidos Mexicanos de 1917}

La Constitución Política de los Estados Unidos Mexicanos de 5 de febrero de 1917 sustituyó a la de 1857, y se encuentra en vigor.

36 "Art. 92. Cada uno de los individuos de la Suprema Corte de Justicia durará en su encargo seis años, y su eleccion será indirecta en primer grado, en los términos que disponga la ley electoral." Antecedentes históricos y Constituciones Políticas de los Estados Unidos Mexicanos, op. cit., p. 263.

37 Museo de las Constituciones, Calle del Carmen núm. 31, Centro Histórico, Ciudad de México, "Constituciones de 1836 y 1843 voto indirecto”, Exposición permanente.

38 De acuerdo con Rolando Tamayo, los tribunales de agravios "están concebidos para restituir a los individuos en el ejercicio de sus derechos". Rolando Tamayo y Salmorán, Introducción al estudio de la Constitución, $2^{\mathrm{a}}$ ed., México, Doctrina Jurídica Contemporánea, 2002, p. 245. 
Conforme a su publicación original, en este ordenamiento constitucional, la Suprema Corte de Justicia de la Nación fungió como un tribunal de agravios y se integró nuevamente por once Ministros. En este rubro resalta que, según el artículo 96, los miembros de la Suprema Corte eran propuestos por las legislaturas de los estados, pero designados por el Congreso General. ${ }^{39}$ En cambio, el Procurador General de la República retornó a la esfera del Ejecutivo, de acuerdo con el artículo 102 constitucional.

La Constitución de 1917 incorporó otros mecanismos de defensa constitucional, "en ella se encuentra como una novedad en materia de defensa de la Constitución, la creación del amparo directo, el que prospera para defender la vigencia y supremacía constitucional junto con el amparo indirecto". ${ }^{40}$

Durante el siglo XX, la carga de trabajo fue el leitmotiv para las modificaciones constitucionales a la estructura del Poder Judicial de la Federación. ${ }^{41}$ Hasta 1928 se modificó el número original de Ministros que integró la Suprema Corte de Justicia, para quedar con dieciséis individuos. En 1934 el número de Ministros acrecentó a veintiuno y en 1951, además de los veintiuno Ministros, se agregaron cinco supernumerarios.

\footnotetext{
39 Antecedentes históricos y Constituciones Politicas de los Estados Unidos Mexicanos, op. cit., p. 339:
}

Art. 96.-Los miembros de la Suprema Corte de Justicia de la Nación serán electos por el Congreso de la Unión en funciones de Colegio Electoral, siendo indispensable que concurran cuando menos las dos terceras partes del número total de diputados y Senadores. La elección se hará en escrutinio secreto y por mayoría absoluta de votos. Los candidatos serán previamente propuestos, uno por cada Legislatura de los Estados, en la forma que disponga la ley local respectiva.

Si no se obtuviere mayoría absoluta en la primera votación, se repetirá entre los dos candidatos que hubieren obtenido más votos.

40 Alberto del Castillo del Valle, Introducción básica al derecho procesal constitucional mexicano, México, Ediciones Jurídicas Alma, 2008, p. 55.

41 Cfr. José Antonio Caballero, op. cit., pp. 165-170. 
Asimismo, la carga de trabajo en el poder judicial aumentó de forma gradual y se reflejó en un rezago constante porque, hasta la creación de los tribunales colegiados de circuito, la Suprema Corte conocía de los amparos en revisión que presentaban las personas de todo el país - en este sentido la Corte era un órgano concentrado- ${ }^{-}$ Por eso se experimentó la creación exponencial de tribunales de circuito y juzgados de distrito en los últimos cincuenta años del siglo pasado. Empero,

la apertura de nuevos tribunales para absorber la demanda de amparos directos genera más amparos. De esta manera, la política expansiva del poder judicial federal de finales de los años noventa y principios del 2000 muestra algunos problemas de planeación. ${ }^{42}$

Aun con la reforma política de 1977, en la que se propuso una liberalización política a cuenta gotas, ${ }^{43}$ la Suprema Corte de Justicia de la Nación se mantuvo alejada de los conflictos políticos, de los demás poderes y de la sociedad en general, en contraposición a las funciones políticas, mas no partidistas, de un auténtico tribunal constitucional.

\section{x. Reforma constitucional del Poder Judicial de la FEdERACIÓN DE 1988}

La reforma constitucional del 10 de agosto de 1987, que entró en vigor hasta el 15 de enero de 1988, tuvo como propósito principal solucionar el gran rezago de trabajo en el Poder Judicial de la Federación, específicamente en la Suprema Corte de Justicia. Para esto fue necesario delimitar aún más las competencias del máximo tribunal del país.

\footnotetext{
42 Ibidem, p. 183.

43 Cfr. César Cansino, El evangelio de la transición y otras quimeras del presente mexicano, México, Debate, 2009, p. 39.
} 
Así, la Corte delegó poco a poco el conocimiento del mayor número de casos en instancias inferiores y, tangencialmente, especializó su control de regularidad en uno de la constitucionalidad, aunque esto no redundó en la instauración de un tribunal constitucional.

En esta reforma judicial también se introdujo la atribución de la Suprema Corte para emitir Acuerdos Generales a fin de distribuir la carga de trabajo entre los órganos del Poder Judicial de la Federación.

Xi. Reforma constitucional del Poder Judicial de la FEDERACIÓN DE 1995

Aunque para algunos académicos, como José Antonio Caballero, la reforma constitucional de 1995 implicó una revolución judicial; ${ }^{44}$ lo cierto es que la reforma constitucional del 31 de diciembre de 1994 -que entró en vigor el $1^{\circ}$ de enero de 1995- significó una metamorfosis de la Suprema Corte de Justicia de la Nación, más que una restructuración de todo el Poder Judicial de la Federación.

A partir de dicha reforma, la Suprema Corte fungió como árbitro de las contiendas entre autoridades porque las circunstancias políticas cambiaron en el país y el poder unipolar del presidente para resolver discordias se desplazó, en parte, hacia el terreno judicial, específicamente hacia la Suprema Corte. ${ }^{45}$ Lo anterior se impulsó con la reconfiguración de la controversia constitucional y la introducción de la acción de inconstitucionalidad.

El diseño institucional de la Suprema Corte de Justicia sufrió la modificación más ostensible desde 1934, debido a que la integración del tribunal en pleno ahora se conforma por once ministros, de conformidad con el artículo 94 de la Constitución Política de los Estados Unidos Mexicanos, para esto se eliminó a los supernumerarios y, por ende, a la sala auxiliar.

\footnotetext{
44 Cffr. José Antonio Caballero, op. cit., p. 178.

45 Idem.
} 
Al respecto, no existe alguna razón en específico que determine este número; es decir, no hay una justificación racional de por qué son once, en vez de nueve, trece o quince ministros.

En la exposición de motivos de la iniciativa de reformas al Poder Judicial de la Federación, presentada en la Cámara de Senadores el 5 de diciembre de 1994 por el Ejecutivo Federal, la justificación para la determinación del número de Ministros fue una remisión al texto original de la constitución de 1917;46 la cual, originalmente, integró la Suprema Corte de Justicia con once miembros. Sin embargo, los Constituyentes de 1917 se inspiraron a su vez en la Constitución de 1857 para determinar el número de integrantes, la Constitución mexicana de 1857 retomó la integración de la Suprema Corte que se estableció en las Bases Orgánicas de 1843 -de carácter centralista- y, más aún, esta integración se decantó de la Constitución Federal de 1824.

De modo que, la verdadera razón por la que la Suprema Corte de Justicia de la Nación se compone actualmente por once Ministros es por una transmisión indeliberada del número de sus integrantes desde la Constitución de 1824.

Con la reforma judicial de 1995 se observaron transformaciones como la introducción del Consejo de la Judicatura Federal, órgano encargado de la administración, vigilancia, disciplina y carrera judicial del Poder Judicial de la Federación, con excepción de la Suprema Corte de Justicia y el Tribunal Electoral del Poder Judicial de la Federación, así como el inicio de la novena época del Semanario Fudicial de la Federación.

46 "En lo concerniente a la integración de la Suprema Corte de Justicia de la Nación, se prevé reducir el número de Ministros de 26 a 11, volviendo así al número de miembros establecido en el artículo 94 del texto original de la Constitución de 1917." Exposición de motivos de la iniciativa del Ejecutivo Federal del 5 de diciembre de 1994. Página electrónica de la Suprema Corte de Fusticia de la Nación, sección normativa nacional, disponible en: <http://bovmsilap.scjn.pjf.gob.mx/Buscador/Paginas/wfProcesoLegislativoCompleto.aspx?IdOrd=130\&IdRef=133\&I$\mathrm{d}$ Proc $=1>$, [Fecha de consulta: 21 de diciembre de 2015]. 
El presupuesto para el Poder Judicial de la Federación tuvo un incremento y se dio una apertura judicial como nunca antes se había dado. "Inició un importante proceso de apertura que incluye una renovación de la página de Internet, el acceso a las sentencias, la publicidad de los debates de los Ministros y la puesta en funcionamiento del Canal Judicial". ${ }^{47}$

Pero también se registran persistencias como el crecimiento sostenido de los órganos del poder judicial, el rezago en la resolución de asuntos, la diferencia entre los presupuestos asignados al poder judicial de la federación y los de los estados, ${ }^{48}$ y la corrupción.

\section{La Décima Época}

En la Décima Época del Semanario Fudicial de la Federación y su Gaceta, que inició el 4 de octubre de 2011 a raíz de la reforma constitucional de 10 de junio de 2011 y de la resolución del expediente varios 912/2010 (caso Radilla Pacheco), persisten tres posiciones en torno a la naturaleza de la Suprema Corte de Justicia de la Nación.

La primera postura señala que la Suprema Corte es un tribunal constitucional. A su vez, dentro de esta posición se observa que, o se le da plena naturaleza, o se le concibe como un tribunal constitucional sui generis.

La segunda postura "gira en torno a la doble naturaleza de la Suprema Corte de Justicia, como tribunal constitucional y como máxima instancia de la jurisdicción federal". ${ }^{49}$ La tercera niega la naturaleza -formal y material-de la Suprema Corte como tribunal constitucional.

\footnotetext{
47 José Antonio Caballero, op. cit., pp. 190-191.

48 Ibidem, pp. 190-192.

49 Suprema Corte de Justicia de la Nación, Libro Blanco de la Reforma fudicial. Una agenda para la justicia en México, México, Coordinación de Compilación y Sistematización de Tesis de la Suprema Corte de Justicia de la Nación, 2006, p. 117.
} 
La postura institucional de la Suprema Corte es la de reconocerse como un tribunal constitucional. ${ }^{50}$ Aunque también hay voces de disenso al interior del Poder Judicial que ponen énfasis en que la Suprema Corte se encuentra en un proceso de transición inacabado hacia un tribunal constitucional.

Una explicación para la diversidad de posturas respecto a la naturaleza de la Corte, que han generado un debate inconcluso, es la indefinición de ésta en la Constitución general de la República.

El que escribe estas líneas se adhiere a la postura que niega la naturaleza jurídica de la Suprema Corte de Justicia de la Nación como tribunal constitucional. En realidad, la Suprema Corte es un tribunal terminal del Poder Judicial de la Federación. Según Emanuel Rosales Guerrero, un tribunal terminal -denominado también tribunal límite o supremo- es:

$[\mathrm{U}] \mathrm{n}$ órgano jurisdiccional de jerarquía que, en el desarrollo de las instancias procesales, representa al que resolverá, en definitiva y de modo absoluto, un juicio, una vía o un recurso.

Tratándose del Poder Judicial de la Federación, los tribunales terminales, en la instancia constitucional, son la Suprema Corte de Justicia de la Nación y los Tribunales Colegiados de Circuito, mientras que en la instancia de legalidad son los Tribunales Unitarios de Circuito.

Los jueces de Distrito adolecen de la característica de tribunales terminales pues sus resoluciones son recurribles. ${ }^{51}$

50 Ese término se utilizó en las jurisprudencias del Pleno de la Suprema Corte, con números de registro digital 160482, 165073 y 177006, y en las publicaciones institucionales: El poder judicial de la Federación para jóvenes, $3^{\mathrm{a}}$ ed., México, Coordinación de Compilación y Sistematización de Tesis de la Suprema Corte de Justicia de la Nación, 2010, p. 117 y La defensa de la Constitución, México, Coordinación de Compilación y Sistematización de Tesis de la Suprema Corte de Justicia de la Nación, 2005, p. 66.

51 Emmanuel Guadalupe Rosales Guerrero, Estudio Sistemático de la jurisprudencia, México, Coordinación de Compilación y Sistematización de Tesis de la Suprema Corte de Justicia de la Nación, 2005, p. 104. 
Entonces, la diferencia entre un tribunal terminal y uno constitucional es que el primero es la última instancia, mientras que el tribunal constitucional es única instancia.

En consecuencia, la Suprema Corte de Justicia de la Nación no es un tribunal constitucional. El primer argumento para sustentar esta tesis consiste en que la Constitución Política de los Estados Unidos Mexicanos no instituye un tribunal constitucional. En ningún artículo de la Constitución federal se usa el término de tribunal constitucional para referirse a la Suprema Corte u otro órgano estatal. De ahí que, un sector de la academia imputa a la Suprema Corte de arrogarse la calidad -y por tanto las atribuciones- de un tribunal constitucional, por no mencionarse dicha naturaleza jurídica en la Constitución federal.

En segundo lugar, la Suprema Corte es la cabeza del Poder Judicial de la Federación. Esta característica impide que pueda ser independiente, autónoma o imparcial respecto al propio Poder Judicial. En tercer lugar, no se trata de un órgano excluyente, por tanto, no se está frente a un órgano altamente especializado ni de tipo concentrado en la materia de control de la constitucionalidad. Por último, el método de nombramiento de los integrantes de la Corte no garantiza un órgano libre de partidización.

Incluso se puede argumentar que, con base en esta última característica - el desequilibrio constitucional en su proceso de integración- la Suprema Corte de Justicia de la Nación es un órgano político de control de la constitucionalidad.

Tampoco es un tribunal de agravios, puesto que la Suprema Corte de Justicia no sólo vela por la protección de los derechos fundamentales - la parte dogmática de la Constitución-, sino que también se encarga de proteger la parte orgánica; por ejemplo, a través de la controversia constitucional.

Inclusive, si se atiende al derecho comparado, se puede concluir que la Suprema Corte de México tiene más similitudes con la Corte Suprema estadounidense que con cualquier tribunal constitucional 
europeo. La Corte Suprema de Estados Unidos de América es "el más alto entre los ordinarios órganos judiciales federales americanos, y a ella, como va subrayado, se llega no mediante procedimientos especiales, sino a través del iter de las impugnaciones y recursos normales". 52

En este sentido, la Suprema Corte de Justicia de la Nación encaja de modo cabal en esta definición, aun cuando conoce de modo exclusivo la controversia constitucional, porque en este proceso los quejosos deben cumplir con el principio de definitividad antes de reclamar ante la Corte.

Cabe resaltar que esta similitud contrasta con el sistema jurídico en el que se desenvuelve cada Corte, ya que el sistema jurídico estadounidense pertenece al Common law mientras que el mexicano es neorromano germánico canónico (civil law o de derecho escrito).

\section{xili. Conclusiones}

Aunque México fue pionero en la instauración de un régimen de control judicial de la constitucionalidad con la adopción del amparo en el siglo XIX, en la historia constitucional mexicana no se registra el establecimiento de un tribunal constitucional en sentido estricto; es decir, no hemos tenido un órgano cuya integración guarde un equilibrio constitucional, especializado en el control de la constitucionalidad y cuyas resoluciones tengan en la mayoría de los casos efectos generales.

De esta concisa investigación se desprende que persisten rasgos decimonónicos en el diseño institucional de la Suprema Corte de Justicia de la Nación.

En síntesis, a pesar de que en México se han hecho reformas judiciales para encauzar al máximo tribunal hacia un órgano concentrado; éstas han terminado por brindarle a la Suprema Corte

52 Mauro Cappelletti, Obras. La justicia constitucional. Dimensiones de la justicia en el mundo contemporáneo, México, Porrúa-UNAM, 2007, p. 72. 
únicamente las características de forma de un tribunal constitucional, por ejemplo: periodos amplios de encargo a los ministros, la prohibición de reelección, establecer la publicidad de sus actuaciones, remuneración inalterable e inamovilidad de sus integrantes.

Sin embargo, las características de fondo, aquéllas que son determinantes para instituirla como un auténtico tribunal constitucional -verbigracia, un órgano exclusivo y excluyente, integrado por especialistas en el control de la constitucionalidad, independiente del poder judicial y con un método democrático de designación de sus integrantes- no se encuentran en el entramado constitucional vigente.

Cabe señalar que las reformas constitucionales de la Décima Época tuvieron impacto en los procedimientos de control de la constitucionalidad, mas no en el diseño institucional del sistema ni en la naturaleza jurídica de nuestro tribunal terminal. Con estas reformas sólo se extendió la característica difusa del control de la constitucionalidad en México.

\section{Xiv. Fuentes}

\section{Bibliográficas}

Arizpe Narro, Enrique, La primera sentencia de amparo, México, Coordinación de Compilación y Sistematización de la Suprema Corte de Justicia de la Nación, 2006.

Caballero, José Antonio. "De la marginalidad a los reflectores. El renacimiento de la administración de justicia en México" en Ilán Bizberg y Lorenzo Meyer (coords.), Una historia Contemporánea de México: Las instituciones, México, Océano-El Colegio de México, 2008, t. 3.

Cansino, César, El evangelio de la transición y otras quimeras del presente mexicano, México, Debate, 2009.

Gappelletti, Mauro, Obras. La justicia constitucional. Dimensiones de la justicia en el mundo contemporáneo, México, Porrúa-UNAM, 2007. 
Córdova Vianello, Lorenzo. "El sistema presidencial en México. Orígenes y Razones" en Miguel Carbonell, (dir.), Ensayos sobre presidencialismo mexicano, México, Aldus, 1994.

Cosío Villegas, Daniel et al., Historia minima de México, México, El Colegio de México, 1983.

Covián Andrade, Miguel, La Sprema Corte y el control de la constitucionalidad (diez años de fallas e imprecisiones), México, CEDIP, 2005.

Del Castillo del valle, Alberto, Introducción básica al derecho procesal constitucional mexicano, México, Ediciones Jurídicas Alma, 2008.

Fix Zamudio, Héctor y Salvador Valencia Carmona, Derecho constitucional mexicano y comparado, $4^{\mathrm{a}}$ ed., México, Porrúa-UNAM, 2005.

Otero, Mariano, "Voto particular de Mariano Otero (5 de abril de 1847)", en La Suprema Corte de Justicia sus leyes y sus hombres, México, Suprema Corte de Justicia de la Nación, 1985, pp. 127-141.

Quiroz Acosta, Enrique, Teoría de la constitución, $3^{\mathrm{a}}$ ed., México, Porrúa, 2005.

Rosales Guerrero, Emmanuel Guadalupe, Estudio sistemático de la jurisprudencia, México, Coordinación de Compilación y Sistematización de Tesis de la Suprema Corte de Justicia de la Nación, 2005.

Schmitт, Carl, La defensa de la constitución. Estudio acerca de las diversas especies y posibilidades de salvaguardia de la constitución, España, Tecnos, 1983.

Secretaría de Gobernación, Antecedentes históricos y constituciones políticas de los Estados Unidos Mexicanos, México, Dirección General de Compilación y Consulta del Orden Jurídico Nacional de la Secretaría de Gobernación, 2006.

Suprema Corte de Justicia de la Nación, Libro blanco de la reforma judicial. Una agenda para la justicia en México, México, Coordinación de Compilación y Sistematización de Tesis de la Suprema Corte de Justicia de la Nación, 2006.

—, El poder judicial de la federación para jóvenes, $3^{\mathrm{a}}$ ed., México, Coordinación de Compilación y Sistematización de Tesis de la Suprema Corte de Justicia de la Nación, 2010. 
— La defensa de la constitución, México, Coordinación de Compilación y Sistematización de Tesis de la Suprema Corte de Justicia de la Nación, 2005.

Tamayo y Salmorán, Rolando, Introducción al estudio de la constitución, $2^{\mathrm{a}}$ ed., México, Doctrina Jurídica Contemporánea, 2002.

—- Razonamiento y argumentación jurídica. El paradigma de la racionalidady la ciencia del derecho, México, UNAM, 2007.

\section{Electrónicas}

Constitución Política del Estado de Mucatán de 1841, <http://www.pdi.uady.mx/ docs/evid02/6.\%20Accin/COMPILACIONES/COMPILA $\% 20$ AMPARO \%20II\%20PDF/constitucoin\%201841.pdf>, [Fecha de consulta: 21 de diciembre de 2015].

Kelsen, Hans, La garantía jurisdiccional de la constitución, Biblioteca Jurídica Virtual del Instituto de Investigaciones Jurídicas de la UNAM, http://www.bibliojuridica.org/libros/libro.htm?l=31, [Fecha de consulta: 21 de diciembre de 2015].

Página electrónica de la Suprema Corte de Fusticia de la Nación, sección normativa nacional, <http://bovmsilap.scjn.pjf.gob.mx/Buscador/Paginas/ wfProcesoLegislativoCompleto.aspx? IdOrd=130\&IdRef $=133 \& \mathrm{I}$ $\mathrm{dProc}=1>$, [Fecha de consulta: 21 de diciembre de 2015].

Pérez Johnston, Raúl, El Supremo poder conservador y su sentencia de muerte: la ley sobre ladrones del 13 de marzo de 1840, Biblioteca Jurídica Virtual del Instituto de Investigaciones Jurídicas de la UNAM, <http:// biblio.juridicas.unam.mx/libros/6/2556/22.pdf>, [Fecha de consulta: 21 de diciembre de 2015].

\section{Hemerográficas}

Jurisprudencia P./J. 136/2005, Semanario Fudicial de la Federación y su Gaceta (Novena Época), Tomo XXII, octubre de 2005, p. 2062. Número de registro digital: 177006 . 
Tesis aislada P. LXV/2011 (9a.), Semanario Fudicial de la Federación y su Gaceta (Décima Época), libro III, diciembre de 2011, tomo 1, p. 556. Número de registro digital: 160482.

Tesis aislada P. XXIX/2010, Semanario Fudicial de la Federación y su Gaceta (Novena Época), tomo XXXI, marzo de 2010, p. 7. Número de registro digital: 165073 .

4. Otras fuentes

Museo de las Constituciones, Calle del Carmen núm. 31, Centro Histórico, Ciudad México, "Constituciones de 1836 y 1843 Voto indirecto", Exposición permanente. 